\title{
Selective pharmacological inhibition of the sodium- dependent phosphate cotransporter NPT2a promotes phosphate excretion
}

\author{
Valerie Clerin, ${ }^{1}$ Hiroshi Saito, ${ }^{2}$ Kevin J. Filipski, ${ }^{1}$ An Hai Nguyen, ${ }^{1}$ Jeonifer Garren, ${ }^{1}$ Janka Kisucka, ${ }^{1}$ Monica Reyes, ${ }^{2}$ and Harald Jüppner ${ }^{2,3}$ \\ 1Pfizer Inc., Worldwide Research, Development and Medical, Cambridge, Massachusetts, USA. Endocrine Unit and ${ }^{3}$ Pediatric Nephrology Unit, Massachusetts Ceneral Hospital (MCH) and Harvard Medical \\ School, Boston, Massachusetts, USA.
}

\begin{abstract}
The sodium-phosphate cotransporter NPT2a plays a key role in the reabsorption of filtered phosphate in proximal renal tubules, thereby critically contributing to phosphate homeostasis. Inadequate urinary phosphate excretion can lead to severe hyperphosphatemia as in tumoral calcinosis and chronic kidney disease (CKD). Pharmacological inhibition of NPT2a may therefore represent an attractive approach for treating hyperphosphatemic conditions. The NPT2a-selective smallmolecule inhibitor PF-06869206 was previously shown to reduce phosphate uptake in human proximal tubular cells in vitro. Here, we investigated the acute and chronic effects of the inhibitor in rodents and report that administration of PF06869206 was well tolerated and elicited a dose-dependent increase in fractional phosphate excretion. This phosphaturic effect lowered plasma phosphate levels in WT mice and in rats with CKD due to subtotal nephrectomy. PF-06869206 had no effect on Npt2a-null mice, but promoted phosphate excretion and reduced phosphate levels in normophophatemic mice lacking Npt2c and in hyperphosphatemic mice lacking Fgf23 or Galnt3. In CKD rats, once-daily administration of PF-06869206 for 8 weeks induced an unabated acute phosphaturic and hypophosphatemic effect, but had no statistically significant effect on FCF23 or PTH levels. Selective pharmacological inhibition of NPT2a thus holds promise as a therapeutic option for genetic and acquired hyperphosphatemic disorders.
\end{abstract}

\section{Introduction}

Serum phosphate levels are maintained within normal limits through several mechanisms. These include the regulation of intestinal phosphate absorption through $1,25(\mathrm{OH})_{2}$ vitamin $\mathrm{D}(1,25 \mathrm{D})$ and the sodium-dependent phosphate transporter NPT2b (also referred to as NaPi2b or SLC34A2), as well as the reabsorption of phosphate by 2 renal transporters, NPT2a (also referred to as NaPi2a or SLC34A1) and NPT2c (also referred to as NaPi2c or SLC34A3) (1-4). Expression of the latter transporters at the apical membrane of the proximal renal tubules (PRTs) is controlled by parathyroid hormone (PTH) and fibroblast growth factor 23 (FGF23), two hormones that consequently play important roles in regulating total phosphate balance.

PTH is produced by the parathyroid glands. It binds to the PTH/PTHrP receptor, a Gas-coupled receptor, to stimulate cAMP formation and PKA-dependent downstream events that include the formation of $1,25 \mathrm{D}$, the biologically active vitamin D metabolite, and the downregulation of NPT2a and NPT2c in

Authorship note: VC and HS contributed equally to this work.

Conflict of interest: VC, KJF, and JC are employees of Pfizer Inc. HS, MR, and HJ are employees of MCH. AHN is an employee of Alcon, and JK is an employee of Synchrogenix. $\mathrm{H}$ J is a co-inventor on a patent describing a method to measure FGF23 (Immunoassays, assay methods, antibodies and method of creating antibodies for detecting FGF-23; patent no. US 7,094,551 B2).

Copyright: (5) 2020, American Society for Clinical Investigation.

Submitted: December 11, 2019; Accepted: August 20, 2020; Published: November 9, 2020 Reference information: J Clin Invest. 2020;130(12):6510-6522.

https://doi.org/10.1172/JCl135665. the kidneys. Consequently, a lack of biologically active PTH, as in postsurgical or genetic forms of hypoparathyroidism $(5,6)$, and resistance to this hormone, as in the different forms of pseudohypoparathyroidism $(7,8)$, lead to reduced urinary phosphate excretion and thus hyperphosphatemia, as well as a reduction in $1,25 \mathrm{D}$ formation that contributes to the development of hypocalcemia.

FGF23, another phosphate-regulating hormone, is produced predominantly by osteocytes in bone and possibly by several other cells/tissues, at least when kidney function is impaired (9-13). FGF23 enhances the excretion of phosphate by binding with high affinity to the FGFR1 and its coreceptor KLOTHO, which reduces expression of NPT2a or NPT2c at the apical membrane of the proximal tubules $(14,15)$. However, unlike the rapid phosphaturic effect of PTH, administering recombinant FGF23 or increasing the endogenous levels of this phosphate-regulating hormone does not lead to increased urinary phosphate excretion until several hours after raising the circulating FGF23 levels $(10,16,17)$. Furthermore, in contrast to PTH, FGF23 reduces 1,25D levels by downregulating the expression of Cyp27B1, which encodes the $1 \alpha$-hydroxylase, and by upregulating the expression of Cyp24A1, which encodes the 24-hydroxylase that metabolizes 1,25D (2, $3,10,16)$. Because of these actions on vitamin $\mathrm{D}$ metabolism, patients with osteomalacia due to FGF23-secreting tumors show a rapid decrease in FGF23 levels after tumor removal and, frequently, a profound increase in 1,25D levels, besides normalization of serum phosphate (18-20).

Several different hyperphosphatemic disorders are caused by a lack of biologically active FGF23 or resistance to FGF23, 


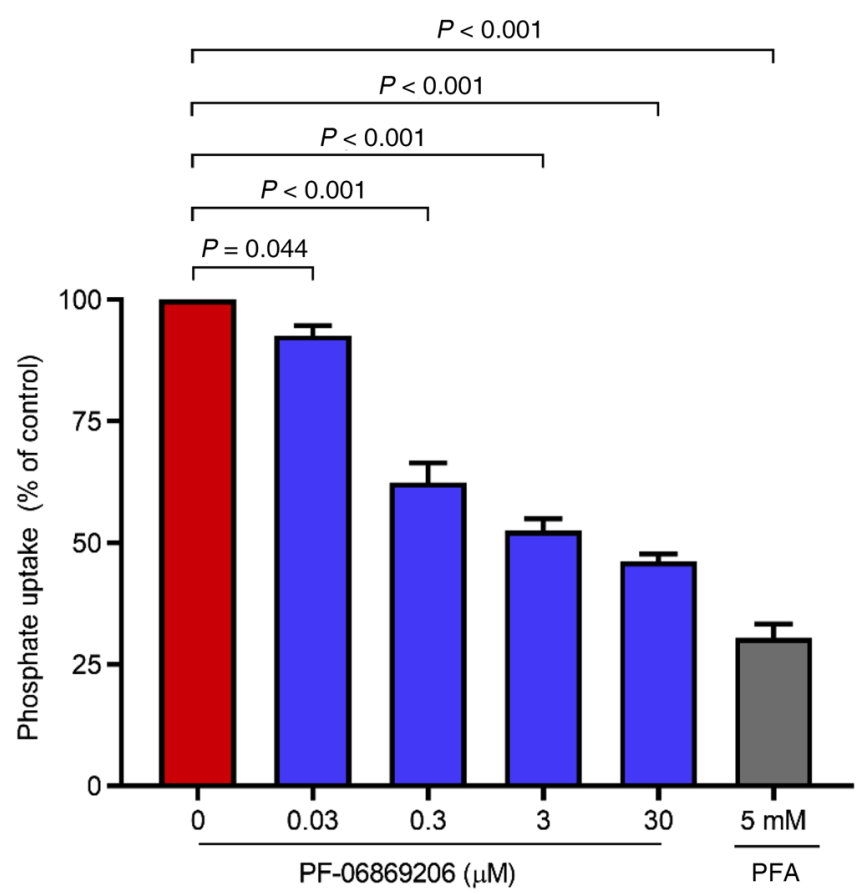

Figure 1. PF-06869206 inhibits phosphate uptake in primary rat PRT cells. PRT cells were treated with increasing doses of PF-06869206 (30 $\mathrm{nM}$ to $30 \mu \mathrm{M}$ ), DMSO vehicle (0 mg/kg PF-06869206), or PFA ( $5 \mathrm{mM}$, positive control) for 30 minutes. ${ }^{32} \mathrm{P}$ was then added to the cells for 5 minutes, and the cells were rinsed to remove unincorporated ${ }^{32} \mathrm{P}$. Phosphate uptake by the cells was derived from cell-associated radioactivity measured after cell lysis. Phosphate uptake data are reported as the percentage of vehicle control and shown as the mean \pm SEM of cells from 3 animals. $P<0.05$, mixed-effects model.

as in different forms of tumoral calcinosis that are caused by homozygous or compound heterozygous, inactivating mutations in FGF23, GALNT3, or KLOTHO (21-26). In contrast, excess FGF23 production or prolonged activity due to "activating" FGF23 mutations leads to an increase in urinary phosphate excretion and thus hypophosphatemia resulting in rickets or osteomalacia, as well as diminished $1,25 \mathrm{D}$ levels $(9,27,28)$. Urinary phosphate wasting and thus hypophosphatemia can also be caused by homozygous or compound heterozygous mutations in NPT2c (29) and particularly in NPT2a (30). These FGF23independent mechanisms enhancing urinary phosphate excretion are associated with mild-to-profound increases in 1,25D production leading to various degrees of hypercalcemia and hypercalciuria $(29,30)$. NPT2a or NPT2c, thus, have a critically important role in regulating serum phosphate levels, and inhibitors of either transporter could therefore be useful for the treatment of different genetic disorders with hyperphosphatemia, particularly the different forms of tumoral calcinosis (21-26).

In addition to inherited disorders involving a lack of or resistance to PTH or FGF23, hyperphosphatemia is highly prevalent in the later stages of chronic kidney disease (CKD). During the early stages of CKD in humans and mice, FGF23 levels increase only slightly, but even these minor elevations appear to be associated with a decline in serum phosphate levels, implying that FGF23 plays an important role in preventing phosphate retention when renal function has just started to decline (31-34). These findings in patients are consistent with studies in rats with mild CKD, in which administration of an anti-FGF23 antibody causes profound increases in serum phosphate levels resulting in vascular calcifications and accelerated mortality (35). As renal dysfunction progresses, FGF23 levels increase further and are associated with more rapid CKD progression and an increased likelihood of premature death (36-38).

Serum phosphate levels are typically normal or in the upper end of the normal range until the glomerular filtration rate (GFR) falls below $30 \mathrm{~mL} / \mathrm{min} / 1.73 \mathrm{~m}^{2}(33,34,39)$. However, even these earlier stages of CKD have been associated with vascular calcifications, increased cardiovascular morbidity, and mortality in humans (37) and rodents (40). Once persistently elevated, the use of oral phosphate binders is approved by the FDA to reduce intestinal phosphate absorption and thereby reduce serum phosphate levels. In animals with CKD, severe dietary phosphate restrictions or the use of extremely high doses of oral phosphate binders effectively reduce, but do not normalize, circulating FGF23 levels; these findings indicate, nonetheless, that phosphate-lowering treatment strategies are effective for limiting the rise in FGF23 $(41,42)$. Unfortunately, an efficient reduction of serum phosphate levels in patients with CKD remains challenging because of gastrointestinal side effects, pill burden, and limited compliance $(43,44)$. Furthermore, a compensatory increase in NPT2b expression has been observed in rodent CKD models (45). Most likely because of a combination of these different reasons, oral phosphate binders have largely failed to elicit the desired reduction in FGF23 levels, even in patients in the early stages of CKD (46-48). This calls into question whether a reduction in the intestinal absorption of phosphate alone is sufficient to prevent the long-term negative effects of impaired phosphate excretion. Consequently, there is a considerable need to identify additional approaches for maintaining normal serum phosphate levels and preventing the rise in FGF23 levels in CKD. Enhancing urinary phosphate excretion may thus have potential utility in the early stages of CKD, and such interventions could be beneficial in patients with different forms of tumoral calcinosis and, possibly as adjunct therapy, in other disorders involving increased serum phosphate levels.

We recently described the discovery of orally bioavailable selective inhibitors of NPT2a that display concentration-dependent inhibition of phosphate uptake in human proximal tubular cells in vitro (49). We showed that the oral pharmacokinetics profile of 1 of these inhibitors, PF-06869206, is suitable for exploring the pharmacological effects of selective NPT2a inhibition in rodents. Here we further characterize the selectivity profile and pharmacological activity of PF-06869206 in vivo and report that it enhanced phosphate excretion in normophosphatemic WT as well as in hyperphosphatemic Fgf23- and Galnt3-null mice (50, 51). Furthermore, acute and long-term treatment of CKD rats with PF-06869206 was well tolerated, and it enhanced urinary phosphate excretion, thereby reducing plasma phosphate levels. Our data obtained in the chronic setting and in hyperphosphatemic mice expand upon the acute in vivo effects shown here and in a recent report (52) by demonstrating that selective NPT2a inhibition holds promise as a 

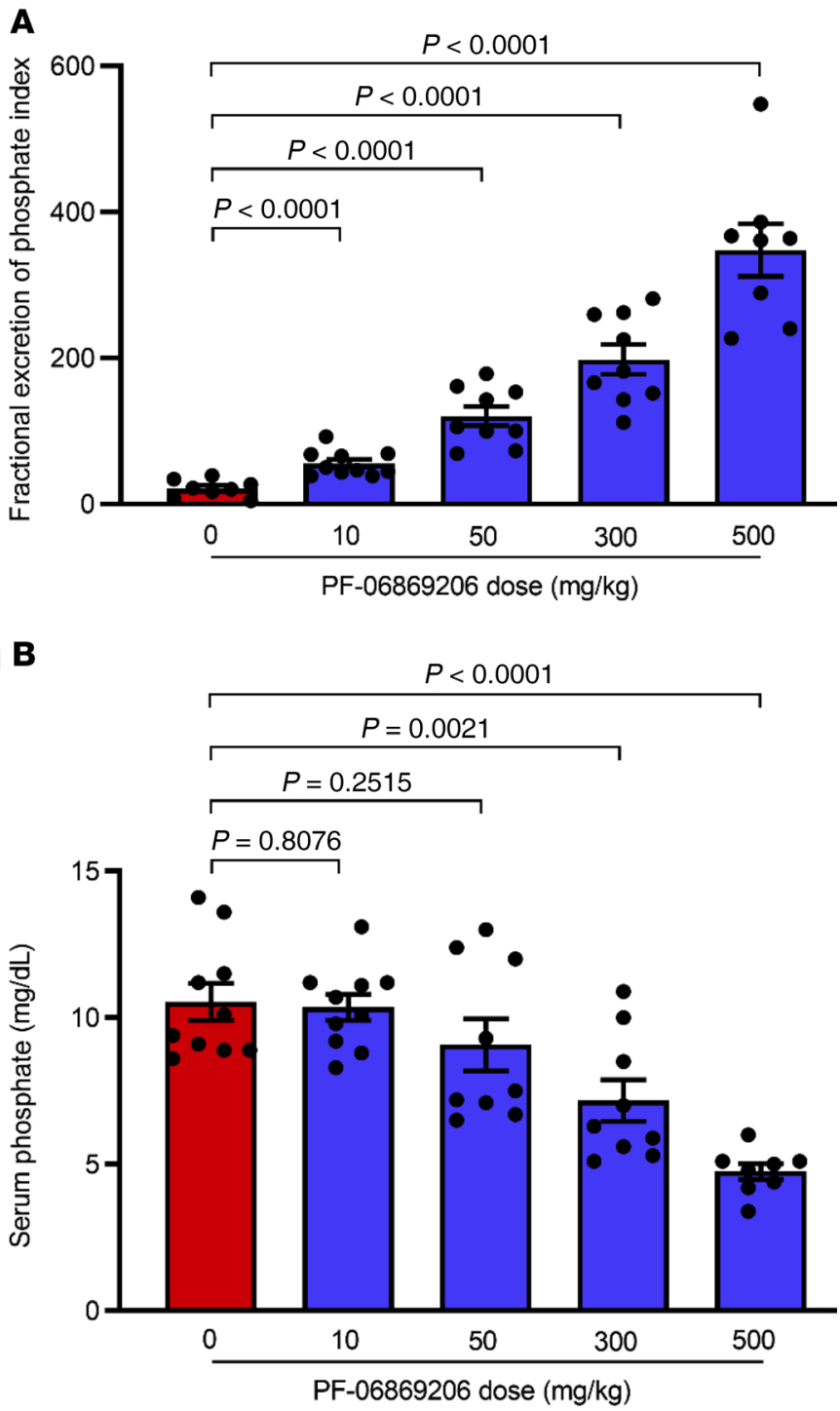

Figure 2. Acute administration of PF-06869206 elicits a dose-dependent increase in urinary phosphate excretion and a reduction of serum phosphate levels in C57BL/6 mice. WT C57BL/6 mice were treated with a single oral dose of PF-06869206 administered at 10, 50, 300, or $500 \mathrm{mg} /$ $\mathrm{kg}$ ( $n=9-10$ mice per dose group) or vehicle (0 mg/kg PF-06869206, $n=8$ mice) and immediately placed in metabolic cages. The $\mathrm{FEI}_{\mathrm{Pi}}(\mathbf{A})$ and serum phosphate levels (B) were derived from analysis of urine and blood samples collected 4 hours after dosing. Data are shown as individual data points and the mean \pm SEM for each dose group. $P<0.05$, mixed-effects model.

therapeutic approach to control serum phosphate in different genetic and acquired hyperphosphatemic disorders.

\section{Results}

Inhibition of NPT2a with PF-06869206 blocks phosphate uptake in vitro. We previously reported the ability of PF-06869206 to reduce phosphate uptake in HEK293 cells stably expressing human, rat, or mouse NPT2a and in primary human proximal tubular cells, but not in cells expressing NPT2b or NPT2c (49). Here, we further characterized the activity profile of PF-06869206 in vitro by measuring phosphate uptake in primary rat PRT cells exposed to increasing concentrations of the inhibitor. PF-06869206 elicited in these cells a statistically significant, concentration-dependent reduction of ${ }^{32} \mathrm{P}$ uptake (Figure 1). The highest dose of PF-06869206 $(30 \mu \mathrm{M})$ resulted in a reduction in radioactivity to $46.2 \% \pm 1.5 \%$ of control levels, compared with a reduction to $92.6 \% \pm 2.1 \%$ of control radioactivity at the lowest dose of PF-06869206 (30 nM) and a reduction to $30.5 \% \pm$ $2.9 \%$ of control with $5 \mathrm{mM}$ phosphonoformic acid (PFA), a nonselective inhibitor of sodium-phosphate transporters that was used as a positive control (Figure 1). These results, together with the reported favorable pharmacokinetics profile of PF-06869206 in rodents (49), supported our decision to further evaluate the pharmacological activity of the NPT2a inhibitor in vivo.

Acute administration of PF-06869206 reduces phosphate reabsorption in $W T$ mice. To characterize the in vivo activity of PF-06869206, we first investigated its effect in C57BL/6 mice. The single oral administration of PF-06869206 at doses ranging from $10 \mathrm{mg} / \mathrm{kg}$ to $500 \mathrm{mg} / \mathrm{kg}$ elicited a dose-dependent increase in the fractional excretion of phosphate index $\left(\mathrm{FEI}_{\mathrm{p}}\right)$ (Figure 2A) that was associated with a dose-dependent decrease in serum phosphate levels (Figure 2B) 4 hours after dosing. The lowest inhibitor dose $(10 \mathrm{mg} / \mathrm{kg})$ elicited a statistically significant change in $\mathrm{FEI}_{\mathrm{Pi}}$ compared with vehicle-treated animals (55.8 \pm 5.5 vs. $21.3 \pm 4.2)$ that did not translate into a statistically significant change in serum phosphate levels relative to levels in vehicle-treated animals $(10.4 \pm 0.5 \mathrm{mg} / \mathrm{dL}$ vs. $10.5 \pm 0.6 \mathrm{mg} /$ $\mathrm{dL}$ ). However, the change in both $\mathrm{FEI}_{\mathrm{Pi}}$ and serum phosphate relative to vehicle treatment was statistically significant when the dose of the inhibitor was escalated to $300 \mathrm{mg} / \mathrm{kg}$ and $500 \mathrm{mg} /$ $\mathrm{kg}$, with the $\mathrm{FEI}_{\mathrm{Pi}}$ increasing to $198.3 \pm 20.3$ and $348.0 \pm 35.9$, respectively, and serum phosphate levels decreasing to $7.2 \pm 0.7$ $\mathrm{mg} / \mathrm{dL}$ and $4.8 \pm 0.3 \mathrm{mg} / \mathrm{dL}$, respectively (Figure 2, A and B).

Acute administration of PF-06869206 increases phosphate excretion in WT and Npt2 $2 \mathrm{c}^{-/}$mice, but not in $\mathrm{Npt2a^{-/ }}$ mice. To assess the specificity of PF-06869206 in vivo, WT, Npt2a $\mathrm{a}^{--}$, and

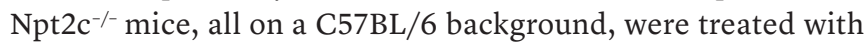
either vehicle or PF-06869206 at $300 \mathrm{mg} / \mathrm{kg}$. Pilot studies had shown maximal effect of the inhibitor 2 and 4 hours after dosing, followed by a decline of the effect (data not shown); $\mathrm{FEI}_{\mathrm{Pi}}$ and plasma phosphate levels were therefore measured before dosing (baseline) and then 2-4 hours and 24 hours after dosing.

Acute administration of $300 \mathrm{mg} / \mathrm{kg}$ PF-06869206 to $\mathrm{Npt}^{2} \mathrm{c}^{-/}$mice (Figure 3, A-D) led to a statistically significant 2.9fold increase in the $\mathrm{FEI}_{\mathrm{Pi}}$ relative to vehicle 2-4 hours after dosing (168.9 \pm 12.0 vs. $58.4 \pm 9.6)$, which was consistent with the statistically significant increase we observed in the $\mathrm{FEI}_{\mathrm{Pi}}$ relative to vehicle in WT mice treated with PF-06869206 at the same dose (116.0 \pm 12.7 vs. $26.0 \pm 4.6)$. Plasma phosphate levels were reduced by $32.6 \%$ relative to vehicle in $\mathrm{Npt}^{2} \mathrm{c}^{-/-}$mice treated with PF- 06869206 at $300 \mathrm{mg} / \mathrm{kg}(6.2 \pm 0.3 \mathrm{mg} / \mathrm{dL}$ vs. $9.2 \pm 0.2 \mathrm{mg} /$ $\mathrm{dL}$ ), which was similar to the reduction in plasma phosphate levels relative to vehicle observed in WT mice treated with the 300 $\mathrm{mg} / \mathrm{kg}$ dose of the inhibitor $(7.4 \pm 0.2 \mathrm{mg} / \mathrm{dL}$ vs. $10.1 \pm 0.2 \mathrm{mg} /$ dL). Twenty-four hours after dosing with PF-06869206 or vehicle, the $\mathrm{FEI}_{\mathrm{Pi}}$ and plasma phosphate levels had returned to baseline in WT and $\mathrm{Npt}^{-\mathrm{c}^{-/}}$mice (Figure 3, A-D).

In contrast to the findings in $\mathrm{WT}$ and $\mathrm{Npt}^{-1 /-}$ mice, administration of PF-06869206 in Npt2a $\mathrm{a}^{-/}$mice failed to increase 
A

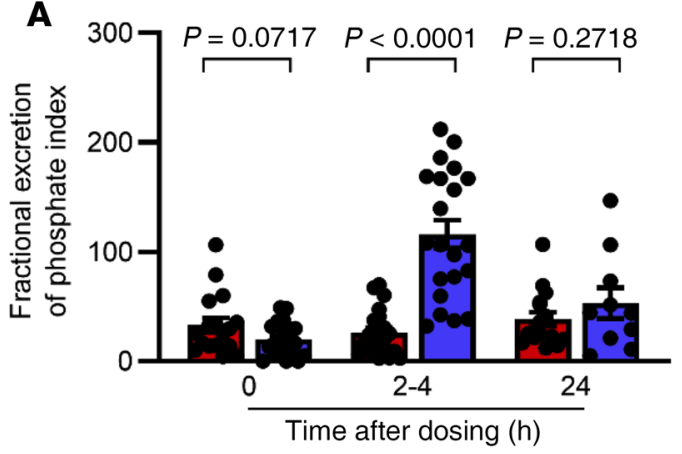

C

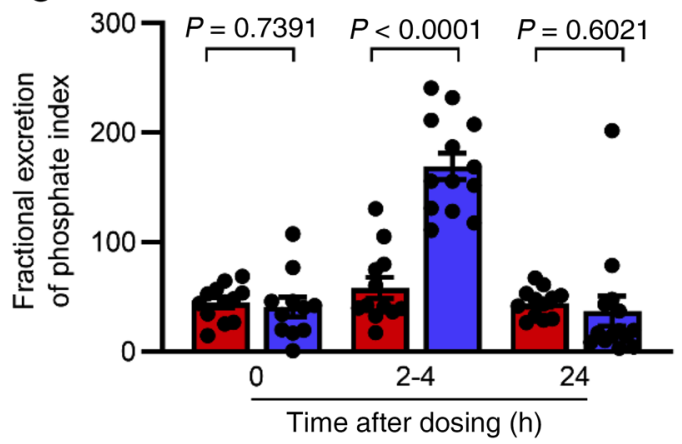

E

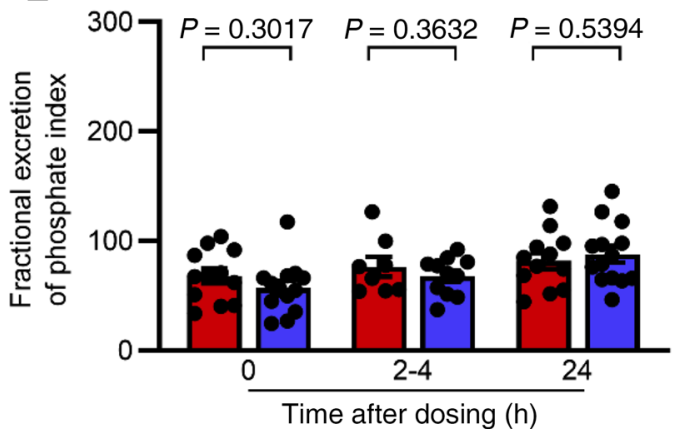

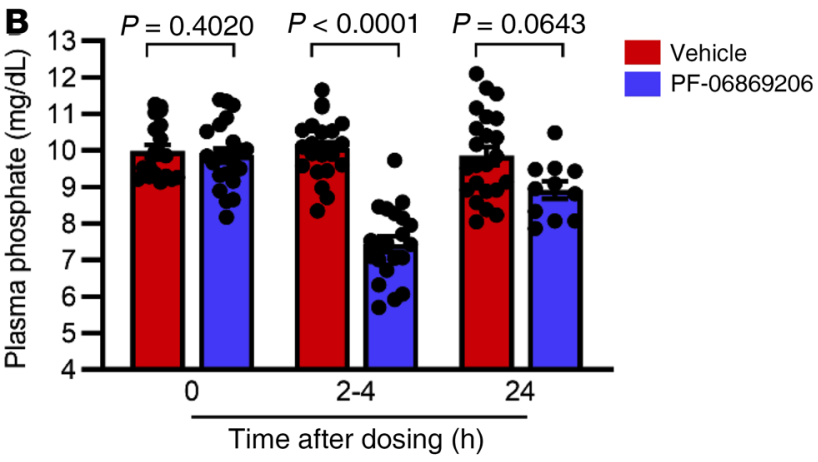

D

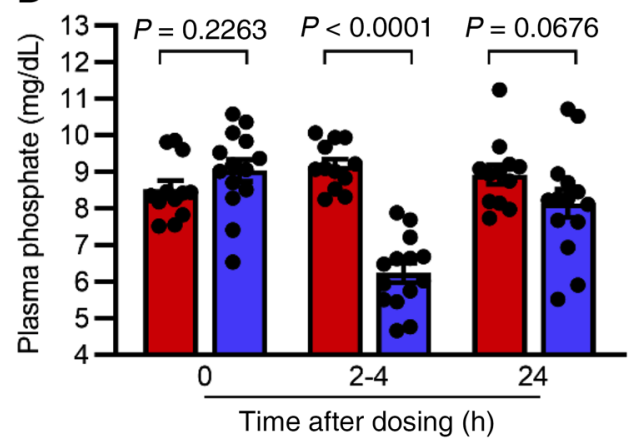

$\mathbf{F}$

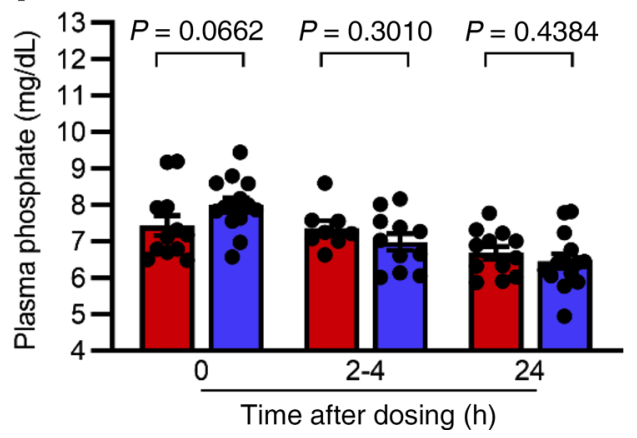

Figure 3. PF-06869206 increases urinary phosphate excretion and reduces plasma phosphate in WT and Npt2c-null mice, but not in Npt2a-null mice. WT mice (A and B), Npt2c-null mice (C and D), and Npt2a-null mice (E and F) were treated with a single oral dose of vehicle (red bars) or PF-06869206 (300 mg/kg, blue bars). Blood and spot urine samples were obtained before treatment ( $n=10-14$ mice per genotype), $2-4$ hours after dosing ( $n=8-23$ mice per genotype) or 24 hours after dosing ( $n=4-14$ mice per genotype). The $\mathrm{FEI}_{\mathrm{pi}}$ ( $\mathbf{A}, \mathbf{C}$, and $\left.\mathbf{E}\right)$ and plasma phosphate levels (B, D, and $\mathbf{F}$ ) are shown. Data are shown as individual data points and the mean \pm SEM for each experimental group. $P<0.05$, by 1 -way ANOVA.

urinary phosphate excretion or to decrease plasma phosphate levels relative to vehicle or baseline levels $2-4$ hours or 24 hours after dosing (Figure 3, E and F). These findings confirmed our in vitro data (49), namely that PF-06869206 selectively inhibited Npt2a and had no readily detectable phosphaturic activity in the absence of that transporter.

Acute administration of PF-06869206 increases calcium excretion in WT mice. We next determined whether the NPT2a inhibitor has an effect on the regulation of calcium homeostasis. WT C57BL/6 mice were given a single dose of either vehicle or PF-06869206 (300 mg/kg) by oral gavage, and blood and urine samples were obtained before treatment and 2, 4 and 24 hours after dosing. Treatment with PF-06869206 did not elicit any statistically significant changes in plasma calcium levels at any of the study time points when compared with treatment with vehicle (Table 1 ). However, a statistically significant, 5 -fold increase in the fractional calcium excretion index
$\left(\mathrm{FEI}_{\mathrm{Ca}}\right)$ was detected 2 hours after dosing with PF-06869206 compared with vehicle treatment, which was associated with a 2.8- and 2.6-fold reduction in PTH levels 2 and 4 hours after treatment, respectively. No statistically significant differences in 1,25D and FGF23 levels in vehicle- and PF-06869206-treated mice were observed at any of the study time points.

Acute administration of PF-06869206 promotes phosphatu-

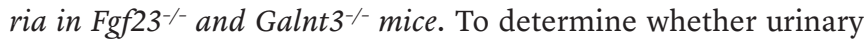
phosphate excretion can be increased in the absence of FGF23, we next treated hyperphosphatemic Fgf23/- mice with a single dose of PF-06869206 (200 mg/kg) or vehicle. Oral gavage with PF-06869206 elicited a 9.1-fold increase in $\mathrm{FEI}_{\mathrm{Pi}}$ in $\mathrm{Fgf}_{23} 3^{-/-}$mice relative to vehicle 4 hours after dosing (158.1 \pm 35.0 vs. $17.4 \pm$ 6.8 ; Figure $4 \mathrm{~A}$ ). This change was associated with a $20.1 \%$ reduction in plasma phosphate levels, from $14.9 \pm 1.0 \mathrm{mg} / \mathrm{dL}$ in vehicle-treated Fgf2 $3^{-/-}$mice, down to $11.9 \pm 0.4 \mathrm{mg} / \mathrm{dL}$ in response to treatment with PF-06869206 (Figure 4B). Differences in $\mathrm{FEI}_{\mathrm{Pi}}$ 
Table 1. PF-06869206 causes an acute increase in $\mathrm{FE}_{\mathrm{ca}}$ and a decrease in PTH(1-84), but does not change plasma calcium, 1,25(OH) $\mathrm{D}$, or intact FGF23 levels in WT mice

\begin{tabular}{lcccccc} 
& Treatment & Plasma Ca, $\mathbf{m g} / \mathbf{d L}$ & $\mathrm{FEI}_{\text {Ca }}$ & PTH(1-84), pg/mL & 1,25(OH) ${ }_{2} \mathbf{D}, \mathbf{n g} / \mathbf{m L}$ & FGF23, pg/mL \\
Time point & & Mean \pm SEM & Mean \pm SEM & Mean \pm SEM & Mean \pm SEM & Mean \pm SEM \\
Baseline & & $10.4 \pm 0.2(n=24)$ & $7.9 \pm 0.5(n=20)$ & $310.1 \pm 25.4(n=26)$ & $3.0 \pm 0.3(n=4)$ & $411.3 \pm 31.4(n=4)$ \\
\multirow{2}{*}{2 hours } & Vehicle & $10.0 \pm 0.6(n=6)$ & $3.6 \pm 1.0(n=6)$ & $256.2 \pm 40.1(n=6)$ & $2.3 \pm 0.3(n=6)$ & $430.4 \pm 44.6(n=6)$ \\
& PF-'206 & $11.4 \pm 0.5(n=6)$ & $18.3 \pm 4.2^{A}(n=6)$ & $91.4 \pm 11.4^{A}(n=7)$ & $1.8 \pm 0.3(n=6)$ & $418.8 \pm 38.4(n=7)$ \\
\multirow{2}{*}{ 4 hours } & Vehicle & $11.9 \pm 0.3(n=6)$ & $3.7 \pm 1.2(n=6)$ & $291.1 \pm 28.3(n=6)$ & $2.6 \pm 0.3(n=6)$ & $435.6 \pm 21.0(n=6)$ \\
& PF-'206 & $11.5 \pm 0.3(n=6)$ & $5.9 \pm 3.1(n=5)$ & $110.9 \pm 29.1^{\mathrm{B}}(n=7)$ & $2.7 \pm 0.4(n=6)$ & $433.5 \pm 25.1(n=7)$ \\
\multirow{2}{*}{ 24 hours } & Vehicle & $10.8 \pm 0.6(n=5)$ & $4.3 \pm 1.6(n=5)$ & $242.1 \pm 41.2(n=7)$ & $1.7 \pm 0.3(n=7)$ & $390.5 \pm 14.6(n=7)$ \\
& PF-'206 & $9.9 \pm 0.5(n=7)$ & $5.9 \pm 1.7(n=7)$ & $191.0 \pm 43.1(n=8)$ & $2.4 \pm 0.2(n=8)$ & $351.0 \pm 31.9(n=8)$
\end{tabular}

WT mice were treated with a single oral dose of vehicle or PF-06869206 (PF-'206) (300 mg/kg). Blood and spot urine samples were obtained from control mice, nontreated mice (baseline), and from mice 2, 4, or 24 hours after dosing. A statistically significant increase in FEI relative to vehicle was observed 2 hours after treatment with PF-06869206, and a statistically significant reduction in PTH(1-84) levels was observed 2 and 4 hours after treatment, whereas plasma calcium levels remained unchanged. No change was observed for $1,25(\mathrm{OH})_{2} \mathrm{D}$ or intact FGF23. ${ }^{A} P<0.05$ versus vehicle 2 hours after dosing; ${ }^{\mathrm{B} P}<0.05$ versus vehicle 4 hours after dosing; 1 -way ANOVA.

or plasma phosphate levels between vehicle- and PF-06869206treated mice were no longer statistically significant by 24 hours after dosing (Figure 4, A and B).

GALNT3 mutations are a more frequent cause of tumoral calcinosis than are FGF23 mutations (53). We therefore tested PF-06869206 also in hyperphosphatemic Galnt3 $3^{-/}$mice, in which a single $300 \mathrm{mg} / \mathrm{kg}$ dose of PF-06869206 led to a statistically significant increase in $\mathrm{FEI}_{\mathrm{Pi}}$ relative to vehicle 2-4 hours after dosing ( $62.5 \pm 8.8$ vs. $121.1 \pm 9.2$; Figure $5 \mathrm{~A})$. This phosphaturic effect was associated with a $21.4 \%$ reduction in plasma phosphate levels to $9.9 \pm 0.3 \mathrm{mg} / \mathrm{dL}$ in mice treated with PF-06869206 relative to levels in mice treated with vehicle (Figure 5B). Similar to the findings in WT mice, plasma calcium levels in vehicle- and inhibitor-treated Galnt3-null mice remained indistinguishable throughout the study $(10.3 \pm 0.29$ vs. $10.0 \pm 0.36 \mathrm{mg} / \mathrm{dL}$ ). The baseline $\mathrm{FEI}_{\mathrm{Ca}}$ was $1.7 \pm 0.19$ for both groups of animals, and this remained unchanged for vehicle-treated mice $2-4$ and 24 hours after treatment $(1.7 \pm 0.36$ and $1.9 \pm 0.27$, respectively), but increased by 5.4 -fold to $9.2 \pm$ 0.43 by $2-4$ hours after dosing with PF-06869206 and returned to $1.8 \pm 0.59$ by 24 hours.

Acute administration of PF-06869206 promotes phosphate excretion in CKD rats. We next assessed the activity of PF-06869206 in the 5/6 nephrectomized rat model of CKD. In this model, serum creatinine was increased to $0.8 \pm 0.1 \mathrm{mg} /$ $\mathrm{dL}$ eight weeks after subtotal removal of renal tissue compared with $0.3 \pm 0.01 \mathrm{mg} / \mathrm{dL}$ in the sham-operated control rats. We detected a dose-dependent increase in fractional excretion of phosphate $\left(\mathrm{FE}_{\mathrm{Pi}}\right)$ four hours after acute administration of $\mathrm{PF}-06869206$ at doses ranging from $10 \mathrm{mg} / \mathrm{kg}$ to $300 \mathrm{mg} /$ $\mathrm{kg}$, with the $300 \mathrm{mg} / \mathrm{kg}$ dose eliciting an 8.8 -fold increase in $\mathrm{FE}_{\mathrm{Pi}}$ relative to vehicle $(26.7 \pm 1.7 \%$ vs. $3.1 \pm 0.7 \%$; Figure $6 \mathrm{~A})$. Increased phosphaturia was associated with a dose-dependent lowering of serum phosphate levels from $6.5 \pm 0.2 \mathrm{mg} /$ $\mathrm{dL}$ in vehicle-treated CKD rats to $4.9 \pm 0.2 \mathrm{mg} / \mathrm{dL}$ in $\mathrm{CKD}$ rats treated with PF-06869206 at a dose of $300 \mathrm{mg} / \mathrm{kg}$ (Figure 6B). Modeling of the exposure- $\mathrm{FE}_{\mathrm{Pi}}$ relationship suggested a trend toward saturation of the effect at the highest dose of $300 \mathrm{mg} /$ kg PF-06869206 administered to CKD rats (data not shown).
Long-term treatment with PF-06869206 is well-tolerated and elicits a sustained pharmacological response in CKD rats. To test whether repeated dosing with PF-06869206 is well tolerated and can persistently lower plasma phosphate levels in a model of CKD, $5 / 6$ nephrectomized rats were treated by oral gavage once daily for 8 weeks with vehicle, PF-06869206 (300 mg/kg), or losartan $(50 \mathrm{mg} / \mathrm{kg}$; an angiotensin receptor blocker used for the treatment of hypertension in CKD); sham-operated rats treated with vehicle served as controls (Supplemental Figure 1; supplemental material available online with this article; https://doi.org/10.1172/ JCI135665DS1). Briefly, we obtained blood and urine samples 2 weeks after the second surgical intervention to measure baseline levels of intact FGF23, bioactive PTH, plasma creatinine levels, the $\mathrm{FEI}_{\mathrm{Pi}}$ and plasma phosphate levels (study day 0); furthermore, baseline systolic blood pressure was determined. We then randomly assigned the animals to treatment with vehicle, PF-06869206, or losartan. Longitudinal $\mathrm{FE}_{\mathrm{Pi}}$ and plasma phosphate levels were determined using urine and blood samples that were collected 4 hours after administration of the first treatment dose (study day 1) and 4 hours after dosing on study days 7, 21, 35, and 49. Systolic blood pressure, intact FGF23, bioactive PTH, and plasma creatinine levels were measured on study days 14, 28, 42, and 56.

We found that baseline plasma creatinine and systolic blood pressure were increased in 5/6 nephrectomized rats compared with sham-operated animals 2 weeks after the second surgical intervention $(0.80 \pm 0.03 \mathrm{mg} / \mathrm{dL}$ vs. $0.35 \pm 0.01 \mathrm{mg} / \mathrm{dL}$, $P<0.0001$, and $171.2 \pm 4.6 \mathrm{mmHg}$ vs. $124.7 \pm 5.8 \mathrm{mmHg}, P<$ 0.0001 , respectively; see below). Furthermore, at baseline, i.e., before treatment with vehicle, PF-06869206, or losartan, all 3 groups of the $5 / 6$ nephrectomized rats showed indistinguishable levels of urinary phosphate excretion $\left(\mathrm{FE}_{\mathrm{P}}: 28.0 \% \pm 2.5 \%, 29.0 \%\right.$ $\pm 1.0 \%$, and $29.5 \% \pm 2.2 \%$, respectively); these levels were higher with statistical significance than those for the sham-operated animals $\left(\mathrm{FE}_{\mathrm{Pi}}: 12.1 \% \pm 0.9 \%\right.$ ) (Supplemental Figure 2A). However, baseline plasma phosphate levels were comparable for all 4 study groups, namely $7.3 \pm 0.2 \mathrm{mg} / \mathrm{dL}$ for the sham-operated rats, and $7.0 \pm 0.2 \mathrm{mg} / \mathrm{dL}, 6.8 \pm 0.2 \mathrm{mg} / \mathrm{dL}$, or $6.9 \pm 0.2 \mathrm{mg} / \mathrm{dL}$ for the CKD rats assigned to treatment with vehicle, PF-06869206, or losartan, respectively (Supplemental Figure 2B). 

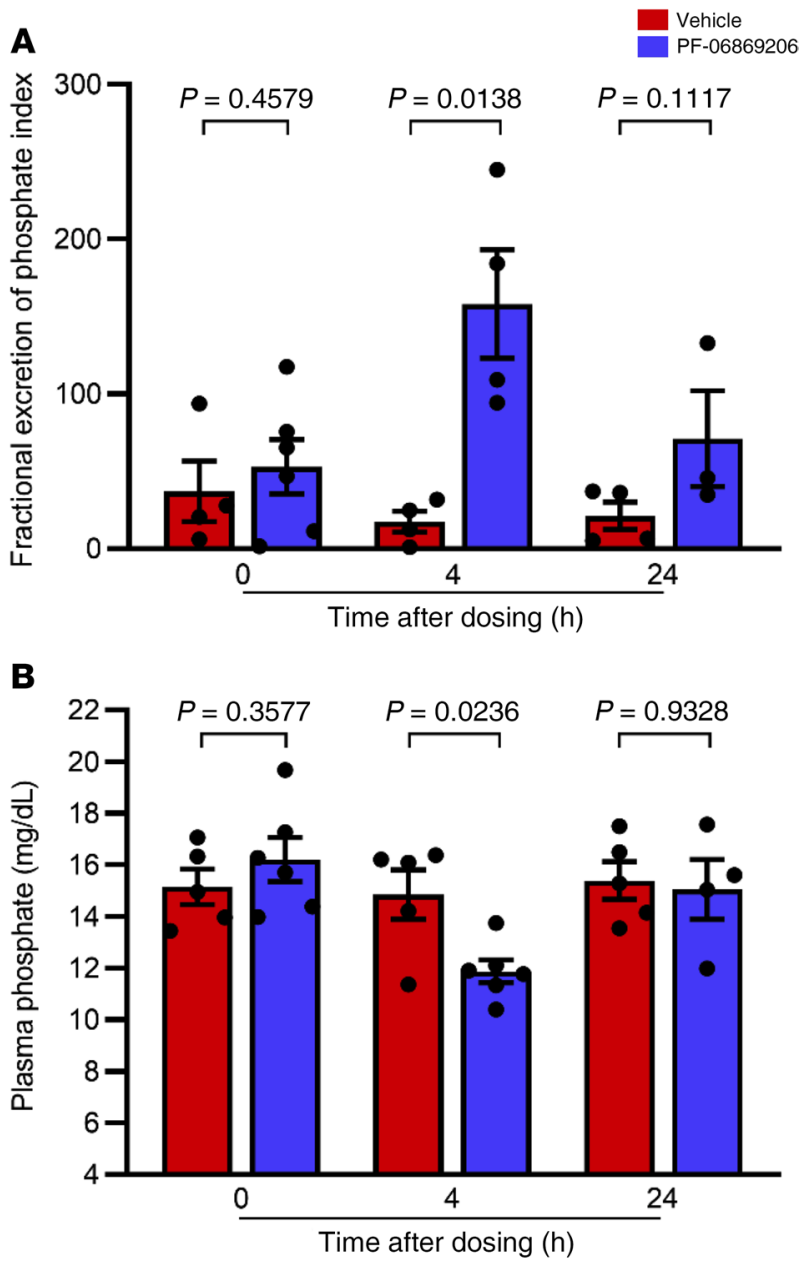

Figure 4. PF-06869206 promotes urinary phosphate excretion and reduces plasma phosphate in Fgf23-null mice. Fgf23-null mice were treated with a single oral dose of vehicle ( $n=5$, red bars) or PF-06869206 (200 mg/kg, $n=6$, blue bars). Blood and spot urine samples were obtained before treatment, 4 hours after dosing, and 24 hours after dosing ( $n=5-6$ mice per treatment group). The $\mathrm{FEI}_{\mathrm{Pi}}(\mathbf{A})$ and plasma phosphate levels (B) are shown. Data are shown as individual data points and the mean \pm SEM for each experimental group. $P<0.05$, by 1-way ANOVA.

Daily dosing with PF-06869206 for 8 weeks was well tolerated as demonstrated by weight gains that were indistinguishable throughout the entire study duration for $5 / 6$ nephrectomized rats receiving vehicle or the NPT2a inhibitor (data not shown). No deaths occurred in the PF-06869206 treatment group. At the end of the study, organ weights (liver, kidney, and heart), as well as the serum liver enzymes alanine aminotransferase (ALT) and aspartate aminotransferase (AST) revealed no difference for $5 / 6$ nephrectomized rats treated with either vehicle or PF-06869206 (data not shown).

On study day 1,5/6 nephrectomized rats showed a statistically significant increase in $\mathrm{FE}_{\mathrm{pi}}$ associated with a decrease in plasma phosphate levels 4 hours after treatment with PF-06869206 relative to vehicle (Figure 7, A-C); this is consistent with the findings in 5/6 nephrectomized rats receiving a single dose of the NPT2a inhibitor (Figure 6). The phosphaturic effect of PF-06869206 was sustained on study days 7, 21, 35, and 49 as indicated by the consistent increase in $\mathrm{FE}_{\mathrm{Pi}} 4$ hours after each dose and the corresponding reduction in plasma phosphate levels (Figure 7, B and C). $\mathrm{FE}_{\mathrm{Pi}}$ remained higher in vehicle- and losartan-treated 5/6 nephrectomized rats compared with sham-operated rats over the duration of treatment, resulting in a trend toward lower plasma phosphate levels that was statistically significant for selected time points in the 5/6 nephrectomized rats compared with sham-operated rats (Figure 7, B and C).

Repeated dosing of the 5/6 nephrectomized rats with PF-06869206 did not reduce plasma creatinine levels or blood pressure relative to vehicle-treated CKD rats (Figure 8, B and C). In contrast, treatment with the angiotensin receptor blocker losartan reduced blood pressure levels in 5/6 nephrectomized animals down to the levels of sham-operated control rats (Figure $8 \mathrm{C}$ ), but did not elicit any change in $\mathrm{FE}_{\mathrm{Pi}}$ or plasma phosphate levels relative to vehicle-treated CKD rats throughout the 8-week study (Figure 7, B and C).

FGF23 and PTH levels were increased at statistically significant levels in 5/6 nephrectomized rats relative to sham-operated animals on study day 0, i.e., 2 weeks after the second surgical intervention $(503.2 \pm 47.5 \mathrm{pg} / \mathrm{mL}$ vs. $281.1 \pm 22.7 \mathrm{pg} / \mathrm{mL}$, $P<0.0001$, and $144.0 \pm 14.4 \mathrm{pg} / \mathrm{mL}$ vs. $53.6 \pm 12.2 \mathrm{pg} / \mathrm{mL}, P<$ 0.0001 , respectively; Figure 9, B and C). Although daily dosing with PF-06869206, which continued for 8 weeks, elicited an unabated increase in $\mathrm{FE}_{\mathrm{Pi}}$ along with a reduction in plasma phosphate levels in 5/6 nephrectomized rats (Figure 7, B and C), we observed no statistically significant decline over time in FGF23 or PTH levels (Figure 9, B and C).

\section{Discussion}

Our studies with PF-06869206 showed that selective pharmacological inhibition of NPT2a promotes efficient and dose-dependent urinary excretion of phosphate, thereby lowering plasma phosphate levels. Urinary phosphate excretion increased by approximately 16-fold with the highest dose of PF-06869206 $(500 \mathrm{mg} / \mathrm{kg})$, resulting in a reduction of plasma phosphate levels of approximately $6 \mathrm{mg} / \mathrm{dL}$ in WT C57BL/6 mice, which is consistent with recently reported findings (52). We observed no obvious saturation of the phosphaturic effect, suggesting that the phosphate-lowering effect could be maximized further, possibly by improving the pharmacokinetics profile or potency of the inhibitor. In addition to its phosphaturic effect, PF-06869206 increased urinary calcium excretion, but no change in plasma calcium concentration was observed, as also shown by Thomas et al. (52). The mechanism underlying the calciuric effect of the NPT2a inhibitor remains unknown. However, it was associated with a decline in PTH levels, which could be sufficient to transiently reduce distal tubular calcium reabsorption. This would imply that elevated extracellular levels of phosphate increase PTH secretion, as recently shown (54); conversely, an acute reduction in blood phosphate levels can lower PTH levels. Our single-dose studies with the NPT2a inhibitor revealed no statistically significant decline in FGF23 levels, which is similar to the observations by Thomas et al. (54).

Consistent with previously reported in vitro data (49), we confirmed specificity of the inhibitor for NPT2a through studies with genetically altered mice. WT and Npt2c-null animals 

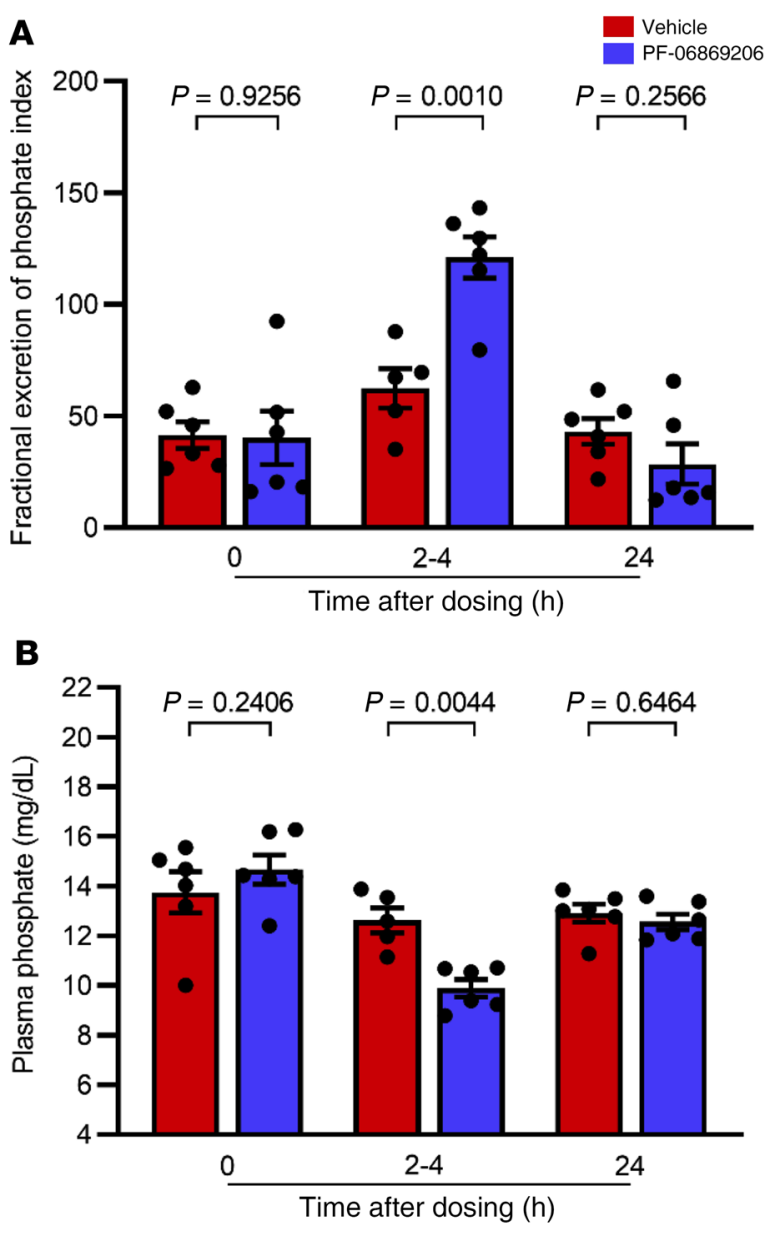

Figure 5. PF-06869206 promotes urinary phosphate excretion and reduces plasma phosphate levels in Galnt3-null mice. Calnt3-null mice were treated with a single oral dose of vehicle ( $n=6$, red bars) or PF-06869206 (300 mg/kg, $n=6$, blue bars). Blood and spot urine samples were obtained before treatment, and 2-4 hours after dosing, and 24 hours after dosing. The $\mathrm{FEI}_{\mathrm{pi}}(\mathbf{A})$ and plasma phosphate levels (B). Data are shown as individual data points and the mean \pm SEM for each experimental group. $P<0.05$, by 1 -way ANOVA.

revealed indistinguishable increases in urinary phosphate excretion in response to treatment with PF-06869206 (300 $\mathrm{mg} / \mathrm{kg}$ ) that in both mouse strains led to similar reductions in plasma phosphate levels. Npt2a-null mice showed lower plasma phosphate levels at baseline compared with WT mice, as expected (55). However, Npt2a-null mice treated with PF-06869206 showed no increase in urinary phosphate excretion and thus no change in plasma phosphate levels, i.e., findings that were indistinguishable from those in vehicle-treated animals. These observations confirmed that, in vivo, PF-06869206 affects only reabsorption of phosphate through NPT2a, the most prominent phosphate transporter, and that the compound does not affect the closely related transporter NPT2c.

PF-06869206 was well tolerated in mice and rats. The lack of obvious side effects is consistent with the in vitro and in vivo selectivity of the inhibitor for NPT2a, as well as the restricted expression of this transporter to the S1-S3 segments of the PRTs (56). It is therefore conceivable that patients with hyperphosphatemia caused by genetic mutations in FGF23, GALNT3, or KLOTHO would benefit from long-term inhibition of NPT2a-dependent phosphate reabsorption with PF-06869206 or an analog thereof (21-26).

This conclusion is supported by our findings with Fgf23null mice $(50,57)$, in which the profound elevation of plasma phosphate was effectively reduced by the NPT2a inhibitor. In comparison with vehicle-treated animals, urinary phosphate excretion increased more than 9-fold in response to a single oral dose of PF-06869206 at $200 \mathrm{mg} / \mathrm{kg}$, thereby reducing blood phosphate levels by approximately $3 \mathrm{mg} / \mathrm{dL}$. We observed similar results in Galnt3-null mice, a second model of tumoral calcinosis, in which urinary phosphate excretion was increased and plasma phosphate levels were reduced upon treatment with PF-06869206. Even such a moderate phosphate-lowering effect could provide meaningful clinical benefits, since a recently reported patient with a compound heterozygous FGF23 mutation had shown, in response to chronic hemodialysis treatment, a similar reduction in blood phosphate levels that resulted in a substantial improvement of his profound extraosseous calcifications (25). Long-term treatment with a NPT2a inhibitor could therefore be helpful in the treatment of patients affected by different forms of tumoral calcinosis (21-26). Likewise, patients with acquired or inherited conditions that can be associated with chronically elevated serum phosphate levels may benefit from adjuvant treatment with an inhibitor of proximal tubular phosphate reabsorption similar to PF-06869206.

Furthermore, pharmacological inhibition of NPT2a is expected to increase urinary phosphate excretion in patients with early-stage CKD, which could reduce the risk of vascular calcification and possibly kidney disease progression and premature mortality. We therefore studied rats that had undergone subtotal nephrectomy, resulting 2 weeks after the second surgical procedure in doubling of plasma creatinine levels, i.e., the equivalent of CKD stage 2-3 in humans. Similar to published findings in rodents with normal renal function and in 5/6 nephrectomized mice (52), our study demonstrated a dose-dependent increase in urinary phosphate excretion in $5 / 6$ nephrectomized rats upon acute administration of PF-06869206. However, the phosphaturic effect was less pronounced than in WT mice, resulting in only a small decline in plasma phosphate levels $(<1.5 \mathrm{mg} / \mathrm{dL})$ at the highest PF-06869206 dose tested (300 $\mathrm{mg} / \mathrm{kg}$ ). This limited response to the NPT2a inhibitor could be related to the substantially reduced mass of functional renal tissue, possibly in combination with an increased total phosphate burden due to prolonged impairment of kidney function. Consequently PF-06869206 may need to be administered to patients with CKD for extended periods of time.

We therefore explored the long-term efficacy of PF-06869206 using animals that had undergone $5 / 6$ nephrectomy and thus had doubled their plasma creatinine level by the time treatment with the NPT2a inhibitor was started. At baseline, vehicle-treated CKD rats showed substantially higher urinary phosphate excretion than did sham-operated animals, which is likely the result of elevations in FGF23 and PTH that had occurred secondary to impaired renal function. Sustained elevations in FGF23 and PTH over the course 


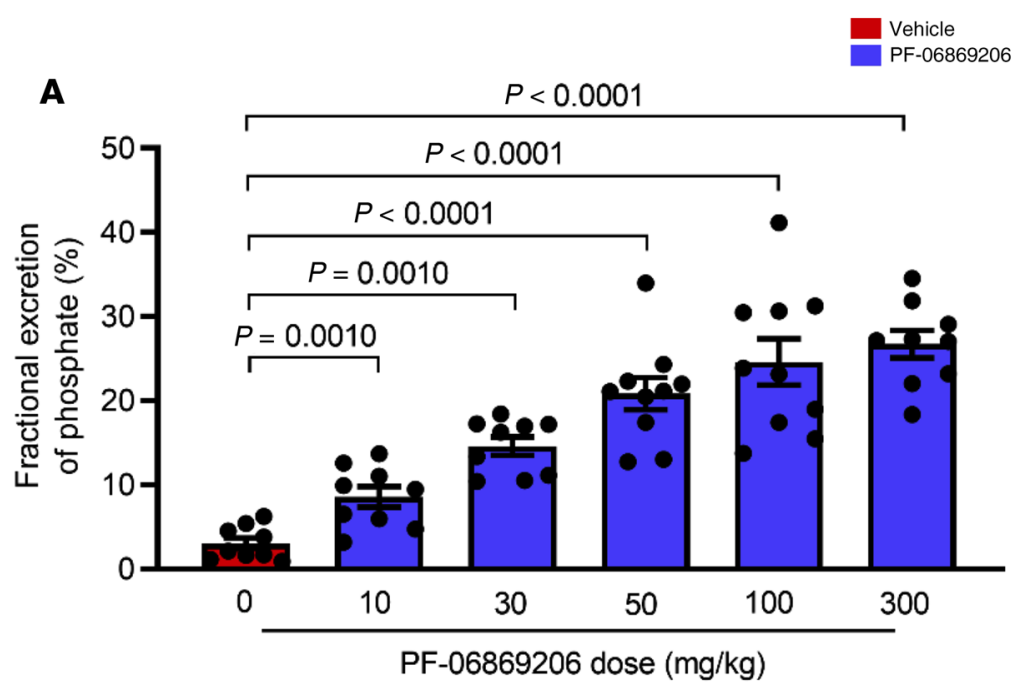

B

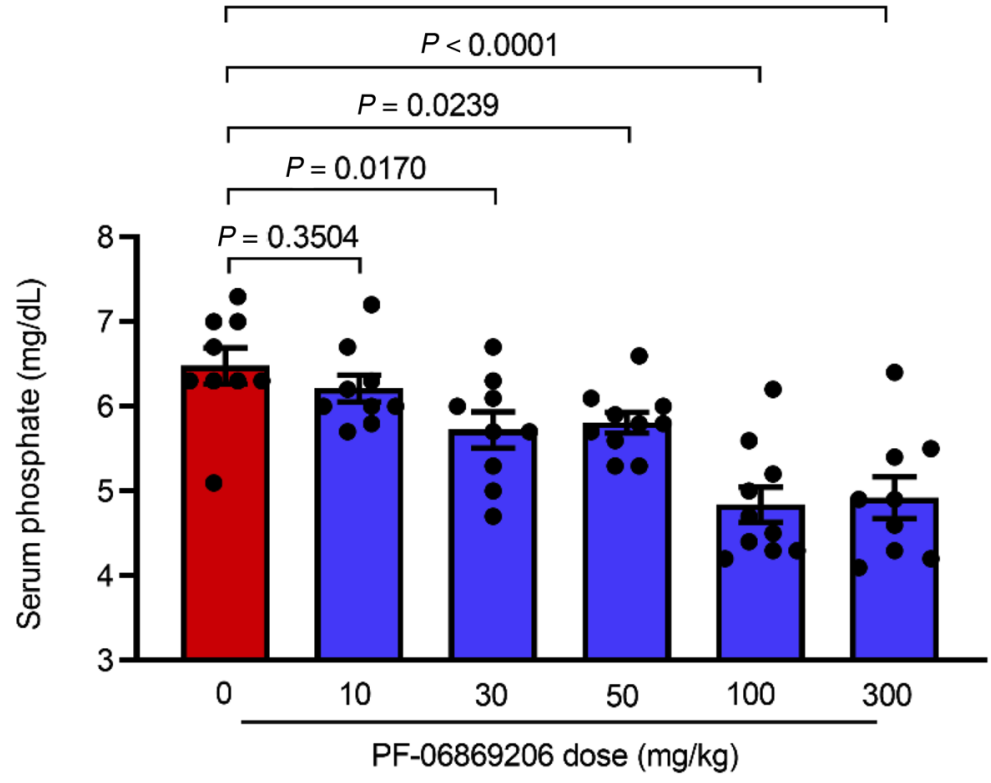

Figure 6. Acute administration of PF-06869206 dose-dependently increases $F_{p i}$ and reduces serum phosphate level in CKD rats. Sprague Dawley rats with CKD due to $5 / 6$ nephrectomy were treated with a single oral dose of PF-06869206 at $10,30,50,100$ or $300 \mathrm{mg} / \mathrm{kg}$ ( $n=9-10$ rats per dose group) or vehicle $(0 \mathrm{mg} / \mathrm{kg}$ PF-06869206, $n=9$ rats). Rats were placed in metabolic cages immediately after dosing, and blood and urine were collected 4 hours after dosing. $\mathrm{FE}_{\mathrm{pi}}(\mathbf{A})$ and serum phosphate levels (B) are shown. Data are shown as individual data points and the mean \pm SEM for each dose group. $P<0.05$, mixed-effects model.

of treatment with vehicle or losartan in $5 / 6$ nephrectomized rats led to sustained phosphaturia at all time points and a trend toward lower plasma phosphate levels at selected time points compared with vehicle-treated, sham-operated rats. Daily administration of PF-06869206 caused a further increase in urinary phosphate excretion in the $5 / 6$ nephrectomized rats, as determined through the use of metabolic cages to collect urine over a 4-hour period after oral dosing. The phosphaturic effect of PF-06869206 was sustained over the 56-day treatment period and led to lower plasma phosphate concentrations at all evaluated time points.
Importantly, treatment with PF-06869206 failed to reduce plasma FGF23 and PTH concentrations, and we observed no change in renal function, as serum creatinine levels remained indistinguishable throughout the study. The NPT2a inhibitor thus failed to lower FGF23 levels despite a substantial increase in urinary phosphate excretion and a statistically significant decline in plasma phosphate levels. It is conceivable that PF-06869206 needs to be administered more frequently to maintain adequate plasma levels or that factors other than phosphate contribute to FGF23 production in CKD. Our studies confirmed those by Thomas et al. (49), namely that an acute reduction in PTH levels occurs in WT mice upon treatment with a single dose of PF-06869206. However, there was no PTH-lowering effect of the NPT2a inhibitor upon repeat dosing in 5/6 nephrectomized rats. Thus, the previously observed acute effect of PF-06869206 on PTH levels in 5/6 nephrectomized mice may not be sustained (49). Additional studies are needed to further explore the role of PF-06869206 on PTH synthesis and secretion.

It is plausible that the phosphaturic response to the NPT2a inhibitor will be different in alternate rodent models of impaired renal function. For example, toxin-induced acute kidney injury (AKI) or CKD, induced by a single injection of folic acid (58) or by the prolonged consumption of adenine-supplemented food (42), respectively, may show little or no phosphaturia in response to treatment with PF-06869206 because of severely impaired, toxicity-induced proximal tubular function. In contrast, mild CKD caused by homozygous Col4 ablation $(32,59)$ or by homozygous, podocyte-specific CTCF-ablation (60) may show a phosphaturic response to the NPT2a inhibitor that is similar to that observed in animals with normal renal function. Long-term PF-06869206 treatment may thus increase fractional phosphate excretion in other CKD models more robustly than that observed in the current 5/6 nephrectomy model, and this may lead to a decline in FGF23 levels.

In summary, PF-06869206, a selective NPT2a inhibitor, promoted urinary phosphate excretion in WT and Npt2c-null mice, without evidence of systemic toxicity. Furthermore, PF-06869206 lowered plasma phosphate levels in hyperphosphatemic Fgf23-null mice and Galnt3-null mice, thus raising the possibility that patients with tumoral calcinosis or other hyperphosphatemic disorders could benefit from treatment with a NPT2a inhibitor. Long-term treatment with PF-06869206 in rats with CKD due to 5/6 nephrectomy resulted in a statistically significant increase in urinary phosphate excretion that reduced plasma phosphate levels. Although the limited hypophosphatemic effect in the current CKD model failed to reduce elevated FGF23 or PTH levels, it is conceivable that other models will show a more pronounced effect. Our results provide evidence that chronic treatment with 


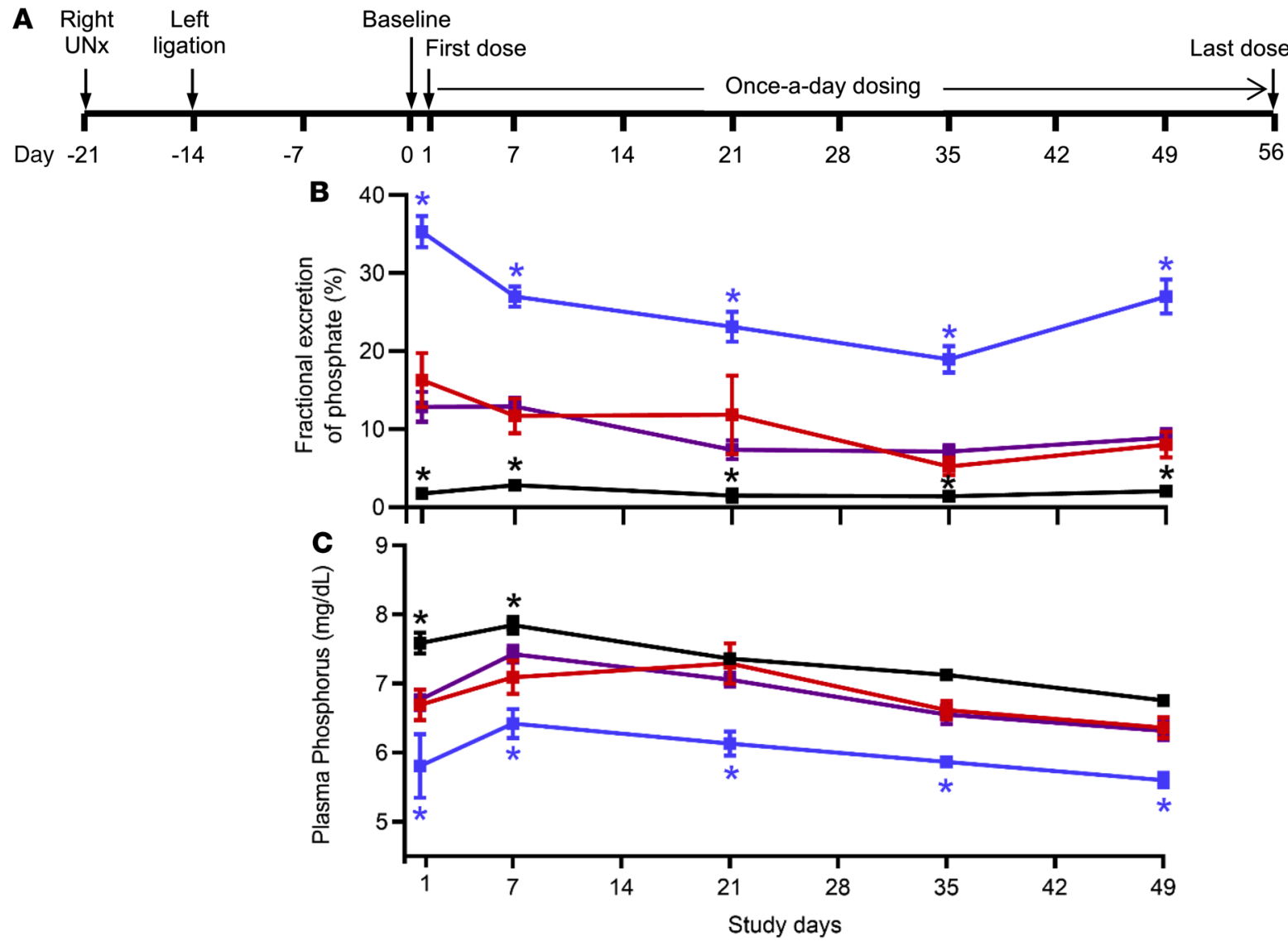

Figure 7. Long-term administration of PF-06869206 elicits sustained daily increases in fractional excretion of phosphate and reductions in plasma phosphate in CKD rats. (A) Sprague Dawley rats with CKD due to right unilateral $5 / 6$ nephrectomy (Right UNx) were treated once daily for 8 weeks with PF-06869206 (300 mg/kg/day, $n=12$ rats, blue line) or vehicle ( $n=12$ rats, red line). $\mathrm{FE}_{\mathrm{pi}}$ (B) and plasma phosphate (C) were derived from analysis of urine and blood samples collected 4 hours after the first treatment dose on study day 1 and on study days 7, 21, 35, and 49. CKD rats receiving $50 \mathrm{mg} / \mathrm{kg} /$ day of the clinical drug losartan ( $n=12$ rats, purple line) for 8 weeks were included for comparison with PF-06869206treated animals. Sham-operated rats treated with vehicle once daily for 8 weeks served as controls $(n=8$, black line). Data are shown as the mean \pm SEM. ${ }^{*} P<0.05$ versus vehicle-treated $5 / 6$ nephrectomized rats, by 1 -way ANOVA.

PF-06869206 or analogs thereof could be suitable for treating both genetic and acquired disorders with impaired phosphate excretion and thus hyperphosphatemia.

\section{Methods}

Isolation of primary rat PRT cells. PRT cells were isolated from the kidneys of Sprague Dawley rats using a protocol adapted from Brown et al. (61). Briefly, cortical slices were minced to approximately pieces $1 \mathrm{~mm}^{3}$ in size that were suspended in isolation medium (RPMI, 5\% FCS, penicillin, streptomycin). The suspension was passed through a $40 \mu \mathrm{m}$ nylon sieve and centrifuged. The resulting cell pellet was resuspended in fresh isolation medium, and centrifugation-resuspension steps were repeated once before the cell suspension was loaded on top of discontinuous Percoll gradients with densities of 1.04 and $1.07 \mathrm{~g} / \mathrm{mL}$ and centrifuged. PRT cells at the intersection of the gradients were aspirated, rinsed, and resuspended in rat renal epithelial growth medium (DMEM/Ham's F-12 basal medium 1:1, $10 \mathrm{mM}$ HEPES, $10 \mathrm{ng} / \mathrm{mL}$ mouse epithelial growth factor, $5 \mathrm{pM} \mathrm{T} 3,3.5 \mu \mathrm{g} / \mathrm{mL}$ ascorbic acid, $5 \mu \mathrm{g} / \mathrm{mL}$ transferrin, $25 \mathrm{ng} / \mathrm{mL}$ PGE, $8.65 \mathrm{ng} / \mathrm{mL}$ sodium selenite, $100 \mu \mathrm{g} / \mathrm{mL}$ G418, $5 \mu \mathrm{g} / \mathrm{mL}$ insulin, $4 \mathrm{mM} \mathrm{L-glutamine,} \mathrm{10 \%} \mathrm{FCS).} \mathrm{The} \mathrm{cell} \mathrm{suspension} \mathrm{was} \mathrm{passed}$ through a large-bore needle 3 times to separate aggregated cells, and the cell yield was quantified using a cell counter.

Phosphate uptake in PRT cells. Freshly isolated PRT cells were resuspended in phosphate-free Krebs buffer $(140 \mathrm{mM} \mathrm{NaCl}, 5.4 \mathrm{mM}$

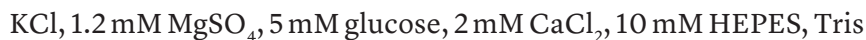
base; $\mathrm{pH}$ 7.4) at a density of 300,000 cells/mL. Vehicle (DMSO) or PF-06869206 (30 nM to $30 \mu \mathrm{M}$ ) was added to the PRT cell suspension for 30 minutes. Sodium phosphate $(100 \mu \mathrm{M})$ labeled with ${ }^{32} \mathrm{P}$ at 1 $\mu \mathrm{Ci} / \mathrm{mL}$ was then added to the cell suspension. After 5 minutes, cells were rinsed in phosphate-free Krebs buffer, transferred to scintillation vials, and lysed with scintillation fluid. Cell-associated radioactivity was detected with a scintillation counter (Beckman Coulter).

Experimental animals. $\mathrm{Npt}_{2} \mathrm{a}^{-/-}$and $\mathrm{Npt}_{2} \mathrm{c}^{-/-}$mice used in the experiments were obtained from The Jackson Laboratory and Hiroko Segawa and Ken-ichi Miyamoto (University of Tokushima, Tokushima, Japan) (56), respectively. Both animals had been backcrossed onto the C57BL/6 background for more than 10 generations; genotyping by PCR amplification of genomic DNA was performed as previously described (62). Fgf $23^{+/-}$mice were provided by Beate Lanske (Harvard Dental School, Boston, Massachusetts, USA) (50), and Galnt $3^{+/-}$mice were provided by Kelly Roszko (NIH), who 

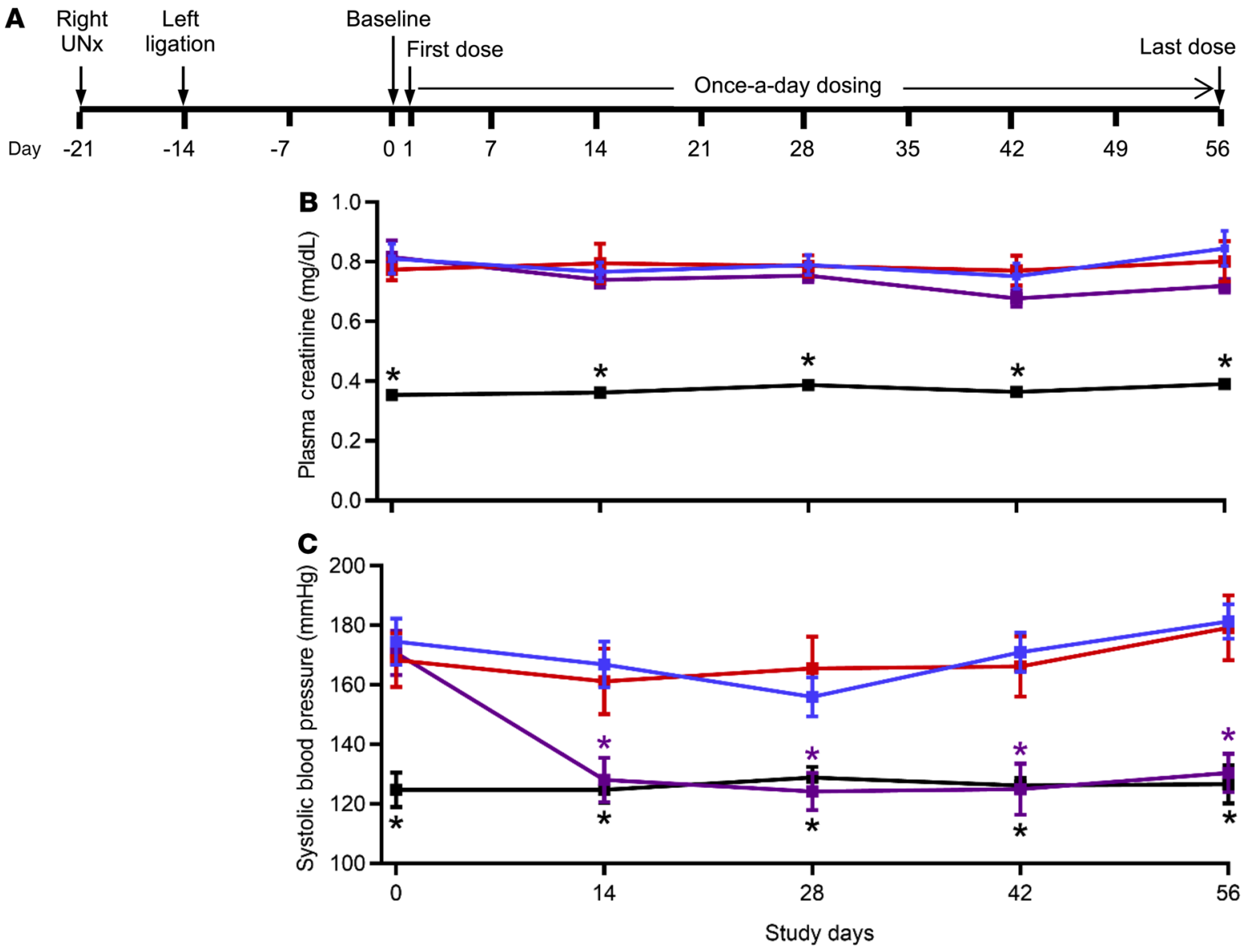

Figure 8. Long-term administration of PF-06869206 does not affect plasma creatinine levels or blood pressure in CKD rats. (A) Sprague Dawley rats with CKD due to $5 / 6$ nephrectomy were treated once daily for 8 weeks with PF-06869206 (300 mg/kg/day, $n=12$ rats, blue line) or vehicle ( $n=$ 12 rats, red line). Plasma creatinine (B) and systolic blood pressure (C) were measured every other week from day 0 (baseline) until day 56 (endpoint). CKD rats receiving $50 \mathrm{mg} / \mathrm{kg} /$ day of the clinical drug losartan ( $n=12$ rats, purple line) for 8 weeks were included for comparison with rats that received PF-06869206. Sham-operated rats treated with vehicle once daily for 8 weeks served as controls $(n=8$, black line). Data are shown as the mean $\pm S E M .{ }^{*} P<0.05$ versus vehicle-treated $5 / 6$ nephrectomized rats, by 1 -way ANOVA.

had obtained them from Michael Econs (51); both animals were on a C57BL/6 background and genotyped as previously described (50, 51). To generate Fgf $23^{-/-}$and Galnt $3^{-/-}$mice, heterozygous males and females of either strain were mated; males and females were used for the experiments. WT C57BL/6 mice served as controls.

Male Spraque Dawley rats with $5 / 6$ nephrectomy were obtained from Charles River Laboratories (surgery code 56NEPHREX) and used in the acute dose-response studies in which PF-06869206 was administered once by oral gavage. For the chronic study, in which the inhibitor was given once daily for 8 weeks, male Spraque Dawley rats were obtained from Charles River Laboratories and underwent right unilateral nephrectomy followed 7 days later by ligation of 3-5 sub-branches of the left primary renal trunk artery; sham-operated rats served as controls.

Mice and rats included in the acute dosing studies were given ad libitum access to a standard rodent diet containing $0.3 \%$ phosphorus (nonphytate, 5053, LabDiet). Sham-operated and 5/6 nephrectomized rats included in the repeat dosing study were provided ad libitum access to a standard rodent diet containing $0.6 \%$ phosphorus (nonphytate, 8640, Harlan Teklad). The time window of treatment administration was consistent across all studies (7-9 am).
Experimental in vivo procedures. PF-06869206 was suspended in $0.5 \%$ methylcellulose and administered to mice or rats by oral gavage at a dosing volume of $10 \mathrm{~mL} / \mathrm{kg}$. In acute studies in which a single ascending dose of PF-06869206 was administered to C57BL/ 6 mice or $5 / 6$ nephrectomized rats, the animals were placed in metabolic cages immediately after compound administration; urine and blood were collected at selected endpoints after dosing. In single-dose administration studies involving $\mathrm{Npt}_{2} \mathrm{a}^{-/-}, \mathrm{Npt}^{2 \mathrm{c}^{-/-}}$, Fgf $23^{-/}$, Galnt $3^{-/-}$mice and WT control mice, the urinary parameters were measured in spot urine samples. In the chronic treatment study in which $5 / 6$ nephrectomized rats were dosed daily with PF-06869206 for 8 weeks, urine samples were collected in metabolic cages, and urine and blood were analyzed at baseline and serially throughout the study period (see Supplemental Figure 1). In this study, blood pressure was measured via indirect tail-cuff plethysmography under light $(0.75 \%)$ isoflurane anesthesia.

Urine and blood sample analysis. Urinary phosphate (uPi), urinary calcium $(\mathrm{uCa})$, urinary creatinine $(\mathrm{uCr})$, serum or plasma phosphate $(\mathrm{Pi})$, plasma calcium $(\mathrm{Ca})$, and serum or plasma creatinine $(\mathrm{Cr})$ were measured either using a clinical chemistry analyzer or spectroscopical measurement assay kits (Abcam for Pi and Stanbio 

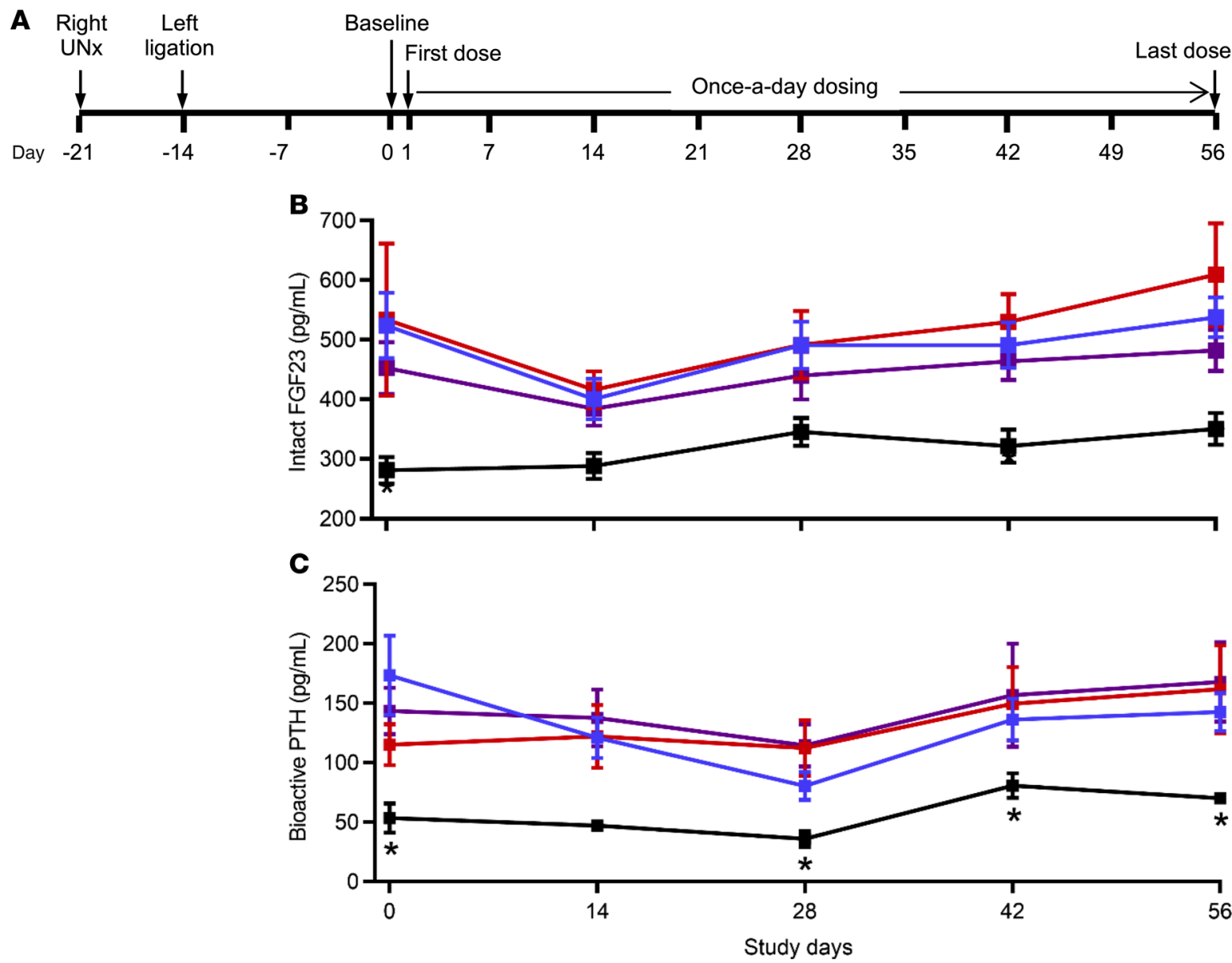

Figure 9. Long-term administration of PF-06869206 does not modulate plasma FGF23 or PTH levels in CKD rats. (A) Sprague Dawley rats with CKD due to $5 / 6$ nephrectomy were treated once daily for 8 weeks with PF-06869206 ( $300 \mathrm{mg} / \mathrm{kg} / \mathrm{day}, n=12$ rats, blue line) or vehicle ( $n=12$ rats, red line). FGF23 (B) and PTH (C) levels were measured every other week from day 0 (baseline) until day 56 (endpoint). CKD rats receiving $50 \mathrm{mg} / \mathrm{kg} /$ day of the clinical drug losartan ( $n=12$ rats, purple line) for 8 weeks were included for comparison with rats that received PF-06869206. Shamoperated rats treated with vehicle once daily for 8 weeks served as controls ( $n=8$, black line). Data are shown as the mean \pm SEM. ${ }^{*} P<0.05$ versus vehicle-treated 5/6 nephrectomized rats, by 1-way ANOVA.

Laboratory for $\mathrm{uCr})$. The $\mathrm{FEI}_{\mathrm{Pi}}$ in mice was calculated as $(\mathrm{uPi} \times 100) /$ $(\mathrm{Pi} \times \mathrm{uCr})$, and the same formula was used to calculate the $\mathrm{FEI}_{\mathrm{Ca}}$ in these animals by replacing $\mathrm{Pi}$ with $\mathrm{Ca}\left(\mathrm{FEI}_{\mathrm{Ca}}\right) . \mathrm{FE}_{\mathrm{Pi}}$ in rats was calculated as $(\mathrm{uPi} \times \mathrm{Cr}) /(\mathrm{Pi} \times \mathrm{uCr})$ (percentage). Intact FGF23 and bioactive intact PTH were measured in plasma by ELISA (Immutopics, 60-6800 and 60-2700, respectively), and 1,25D was determined in plasma using a kit from MyBioSource (MBS2602146).

Statistics. Mixed-effects models with the appropriate correlation structure, terms, and variance adjustments were used to test for associations between treatment groups over time (Figures 3-5 and Figures 7-9). One-way ANOVA with appropriate terms and adjustments to ensure that the assumptions were met was performed to test for associations between treatment groups (Figures 1, 2, and 6, Supplemental Figure 2, and Table 1). To identify a dose-response relationship between treatment groups, appropriate polynomial contrasts were specified. To identify statistically significant associations between treatment groups versus a control group, Dunnett contrasts were specified. To identify any pairwise statistically significant associations between treatment groups, Tukey's contrasts were specified. All multiple comparisons used the FDR adjustment of the $P$ values; a $P$ value of less than 0.05 was considered statistically significant. All analyses were performed using R (version 3.5).

Study approval. All animal studies were conducted as required by the Public Health Service (PHS) Policy on Humane Care and Use of Laboratory Animals and the Animal Welfare Act (AWA). Animals were maintained in accordance with the National Research Council's Guide for the Care and Use of Laboratory Animals (National Academies Press, 2011), and all animal procedures in the protocols were reviewed and approved by IACUCs of Pfizer Inc., MGH, and Plato BioPharma Inc.

\section{Author contributions}

VC, HS, KJF, and HJ conceived, designed, analyzed data and interpreted the results of the studies. JG conducted statistical analysis of all experimental data. HS and AHN performed in vivo experiments, generated data, and contributed to data analysis. JK coordinated the execution of the studies at Plato BioPharma Inc. and contributed to data analysis. MR generated and genotyped all genetically modified mice used in the studies. VC, HS, JG, and HJ wrote the manuscript, and all authors reviewed and/or edited the manuscript. 


\section{Acknowledgments}

The NPT2a-selective small-molecule inhibitor PF-06869206 was provided to MGH by Pfizer through its Compound Transfer Program. The in vitro studies testing the effect of PF-06869206 on phosphate uptake in PRT cells were conducted in the laboratory of Colin D.A. Brown (Newcastle University, Newcastle upon Tyne, United Kingdom). Newcastle University received PF-06869206 through a service agreement between the Pfizer CVMET/IMRU Research Unit and Solvo Biotechnology, a contract research organization (CRO) that works with Newcastle University to provide its services. The long-term in vivo study testing the effect of PF-06869206 in 5/6 nephrectomized rats was conducted at Plato BioPharma Inc. (Westminster, Colorado, USA). Plato BioPharma Inc. is a CRO that received PF-06869206 through a service agreement with the Pfizer CVMET/IMRU Research Unit. This work was supported by NIH grants P01 DK011794 (subproject 3) and DK046718 (to HJ).

Address correspondence to: Valerie Clerin, Pfizer Inc., 1 Portland Street, Cambridge, Massachusetts 02139, USA. Phone: 617.417.5250; Email: Valerie.Clerin@pfizer.com. Or to: Harald Jüppner, 50 Blossom Street, Thier 10, Endocrine Unit, Massachusetts General Hospital and Harvard Medical School, Boston, Massachusetts 02114, USA. Phone: 617.724.7779; Email: HJUEPPNER@mgh.harvard.edu. AHN's present address is: Alcon, Fort Worth, Texas, USA. JK's present address is: Synchrogenix, Cambridge, Massachusetts, USA.
1. Farrow EG, White KE. Recent advances in renal phosphate handling. Nat Rev Nephrol. 2010;6(4):207-217.

2. Tatsumi S, Miyagawa A, Kaneko I, Shiozaki Y, Segawa H, Miyamoto K. Regulation of renal phosphate handling: inter-organ communication in health and disease. J Bone Miner Metab. 2016;34(1):1-10.

3. Christov M, Jüppner H. Endocrine regulation of phosphate homeostasis. In: Uribarri J, Calvo MS, eds. Dietary Phosphorus Health, Nutrition, and Regulatory Aspects. CRC Press; 2017:71-82.

4. Levi M, et al. Mechanisms of phosphate transport. Nat Rev Nephrol. 2019;15(8):482-500.

5. Mitchell DM, et al. Long-term follow-up of patients with hypoparathyroidism. J Clin Endocrinol Metab. 2012;97(12):4507-4514

6. Clarke BL, et al. Epidemiology and diagnosis of hypoparathyroidism. JClin Endocrinol Metab. 2016;101(6):2284-2299.

7. Tafaj O, Jüppner H. Pseudohypoparathyroidism: one gene, several syndromes. J Endocrinol Invest. 2017;40(4):347-356.

8. Linglart A, Levine MA, Jüppner H. Pseudohypoparathyroidism. Endocrinol Metab Clin North Am 2018;47(4):865-888.

9. ADHR Consortium. Autosomal dominant hypophosphataemic rickets is associated with mutations in FGF23. Nat Genet. 2000(3):345-348.

10. Shimada $\mathrm{T}$, et al. Cloning and characterization of FGF23 as a causative factor of tumor-induced osteomalacia. Proc Natl Acad Sci U S A. 2001;98(11):6500-6505.

11. Bonewald LF. The amazing osteocyte. J Bone Miner Res. 2011;26(2):229-238.

12. Rabadi S, Udo I, Leaf DE, Waikar SS, Christov M. Acute blood loss stimulates fibroblast growth factor 23 production. Am J Physiol Renal Physiol. 2018;314(1):F132-F139.

13. Toro L, et al. Erythropoietin induces bone marrow and plasma fibroblast growth factor 23 during acute kidney injury. Kidney Int . 2018;93(5):1131-1141.

14. Urakawa I, et al. Klotho converts canonical FGF receptor into a specific receptor for FGF23. Nature. 2006;444(7120):770-774.

15. Tomoe Y, et al. Phosphaturic action of fibroblast growth factor 23 in Npt2 null mice. Am J Physiol Renal Physiol. 2010;298(6):F1341-F1350.

16. Shimada T, et al. Mutant FGF-23 responsible for autosomal dominant hypophosphatemic rickets is resistant to proteolytic cleavage and causes hypophosphatemia in vivo. Endocrinology. 2002;143(8):3179-3182.

17. Scanni R, vonRotz M, Jehle S, Hulter HN, Krapf R. The human response to acute enteral and parenteral phosphate loads. JAm Soc Nephrol. 2014;25(12):2730-2739.

18. Yamazaki Y, et al. Increased circulatory level of biologically active full-length FGF-23 in patients with hypophosphatemic rickets/osteomalacia. J Clin Endocrinol Metab. 2002;87(11):4957-4960.

19. Jonsson KB, et al. Fibroblast growth factor 23 in oncogenic osteomalacia and X-linked hypophosphatemia. N Engl J Med. 2003;348(17):1656-1663.

20. Imel EA, et al. Sensitivity of fibroblast growth factor 23 measurements in tumor-induced osteomalacia. JClin Endocrinol Metab. 2006;91(6):2055-2061.

21. Topaz O, et al. Mutations in GALNT3, encoding a protein involved in $\mathrm{O}$-linked glycosylation, cause familial tumoral calcinosis. Nat Genet. 2004;36(6):579-581.

22. Frishberg $Y$, et al. Identification of a recurrent mutation in GALNT3 demonstrates that hyperostosis-hyperphosphatemia syndrome and familial tumoral calcinosis are allelic disorders. $J \mathrm{Mol}$ Med. 2005;83(1):33-38.

23. Ichikawa S, et al. A homozygous missense mutation in human KLOTHO causes severe tumoral calcinosis. J Clin Invest. 2007;117(9):2684-2691.

24. Bergwitz C, et al. Defective O-glycosylation due to a novel homozygous S129P mutation is associated with lack of fibroblast growth factor 23 secretion and tumoral calcinosis. JClin Endocrinol Metab. 2009;94(11):4267-4274.

25. Goldenstein PT, et al. Dialysis as a treatment option for a patient with normal kidney function and familial tumoral calcinosis due to a compound heterozygous FGF23 mutation. Am J Kidney Dis. 2018;72(3):457-461.

26. Ichikawa $S$, et al. Clinical variability of familial tumoral calcinosis caused by novel GALNT3 mutations. Am JMed Genet A. 2010;152A(4):896-903.

27. Shimada T, et al. Transgenic mice expressing fibroblast growth factor 23 (FGF23) demonstrate hypophosphatemia with low serum 1,25-dihydroxyvitamin D [1,25(OH)2D] and rickets/osteomalacia. J Bone Mineral Res. 2001:16(suppl 1). Twenty-third Annual Meeting of the American Society for Bone and Mineral Research abstract 1059.

28. Bai XY, Miao D, Goltzman D, Karaplis AC.
The autosomal dominant hypophosphatemic rickets $\mathrm{R} 176 \mathrm{Q}$ mutation in fibroblast growth factor 23 resists proteolytic cleavage and enhances in vivo biological potency. J Biol Chem. 2003;278(11):9843-9849.

29. Dasgupta D, et al. Mutations in SLC34A3/NPT2c are associated with kidney stones and nephrocalcinosis. J Am Soc Nephrol. 2014;25(10):2366-2375.

30. Schlingmann KP, et al. Autosomal-recessive mutations in SLC34A1 encoding sodium-phosphate cotransporter $2 \mathrm{~A}$ cause idiopathic infantile hypercalcemia. J Am Soc Nephrol. 2016;27(2):604-614.

31. Gutierrez O, et al. Fibroblast growth factor-23 mitigates hyperphosphatemia but accentuates calcitriol deficiency in chronic kidney disease. JAm Soc Nephrol. 2005;16(7):2205-2215.

32. Stubbs JR, et al. Longitudinal evaluation of FGF23 changes and mineral metabolism abnormalities in a mouse model of chronic kidney disease. J Bone Miner Res. 2012;27(1):38-46.

33. Block GA, et al. Phosphate homeostasis in CKD: report of a scientific symposium sponsored by the National Kidney Foundation. Am J Kidney Dis. 2013;62(3):457-473.

34. Portale A, et al. Disordered FGF23 and minera metabolism in the chronic kidney disease in children (CKiD) cohort. Clin JAm Soc Nephrol. 2014;9(2):344-353.

35. Shalhoub V, et al. FGF23 neutralization improves chronic kidney disease-associated hyperparathyroidism yet increases mortality. J Clin Invest. 2012;122(7):2543-2553.

36. Fliser D, et al. Fibroblast growth factor 23 (FGF23) predicts progression of chronic kidney disease: the Mild to Moderate Kidney Disease (MMKD) Study. JAm Soc Nephrol. 2007;18(9):2600-2608.

37. Isakova T, et al. Fibroblast growth factor 23 and risks of mortality and end-stage renal disease in patients with chronic kidney disease. JAMA. 2011;305(23):2432-2439.

38. Gutiérrez OM, et al. Fibroblast growth factor 23 and mortality among patients undergoing hemodialysis. N Engl JMed. 2008;359(6):584-592.

39. Block GA, Hulbert-Shearon TE, Levin NW, Port FK. Association of serum phosphorus and calcium $\mathrm{x}$ phosphate product with mortality risk in chronic hemodialysis patients: a national study. Am J Kidney Dis. 1998;31(4):607-617.

40. Fang Y, Ginsberg C, Sugatani T, Monier-Faugere 
MC, Malluche H, Hruska KA. Early chronic kidney disease-mineral bone disorder stimulates vascular calcification. Kidney Int. 2014;85(1):142-150.

41. Ritter CS, Martin DR, Lu Y, Slatopolsky E, Brown AJ. Reversal of secondary hyperparathyroidism by phosphate restriction restores parathyroid calcium-sensing receptor expression and function. J Bone Miner Res. 2002;17(12):2206-2213.

42. Nagano N, et al. Effect of manipulating serum phosphorus with phosphate binder on circulating $\mathrm{PTH}$ and FGF23 in renal failure rats. Kidney Int. 2006;69(3):531-537.

43. Covic A, Rastogi A. Hyperphosphatemia in patients with ESRD: assessing the current evidence linking outcomes with treatment adherence. BMC Nephrol. 2013;14:153.

44. Wang S, Alfieri T, Ramakrishnan K, Braunhofer P, Newsome BA. Serum phosphorus levels and pill burden are inversely associated with adherence in patients on hemodialysis. Nephrol Dial Transplant. 2014;29(11):2092-2099.

45. Sabbagh Y, et al. Intestinal Npt2b Plays a major role in phosphate absorption homeostasis. J Am Soc Nephrol. 2009;20(11):2348-2358.

46. Oliveira RB, et al. Early control of PTH and FGF23 in normophosphatemic CKD patients: a new target in CKD-MBD therapy? Clin JAm Soc Nephrol. 2010;5(2):286-291.

47. Block GA, et al. Effects of phosphate binders in moderate CKD. J Am Soc Nephrol. 2012;23(8):1407-1415.

48. Liabeuf S, et al. Randomized clinical trial of seve- lamer carbonate on serum klotho and fibroblast growth factor 23 in CKD. Clin J Am Soc Nephrol. 2017;12(12):1930-1940.

49. Filipski KJ, et al. Discovery of orally bioavailable selective inhibitors of the sodium-phosphate cotransporter NaPi2a (SLC34A1). ACS Med Chem Lett. 2018;9(5):440-445.

50. Sitara D, et al. Homozygous ablation of fibroblast growth factor-23 results in hyperphosphatemia and impaired skeletogenesis, and reverses hypophosphatemia in Phex-deficient mice. Matrix Biol. 2004;23(7):421-432.

51. Ichikawa S, et al. Ablation of the Galnt3 gene leads to low-circulating intact fibroblast growth factor 23 (Fgf23) concentrations and hyperphosphatemia despite increased Fgf23 expression. Endocrinology. 2009;150(6):2543-2550.

52. Thomas L, Xue J, Murali SK, Fenton RA, Dominguez Rieg JA, Rieg T. Pharmacological Npt2a inhibition causes phosphaturia and reduces plasma phosphate in mice with normal and reduced kidney function. JAm Soc Nephrol. 2019;30(11):2128-2139.

53. Ramnitz MS, et al. Phenotypic and genotypic characterization and treatment of a cohort with familial tumoral calcinosis/hyperostosis-hyperphosphatemia syndrome. J Bone Miner Res. 2016;31(10):1845-1854.

54. Centeno PP, et al. Phosphate acts directly on the calcium-sensing receptor to stimulate parathyroid hormone secretion. Nat Commun. 2019;10(1):4693.
55. Beck L, Karaplis AC, Amizuka N, Hewson AS, Ozawa H, Tenenhouse HS. Targeted inactivation of Npt2 in mice leads to severe renal phosphate wasting, hypercalciuria, and skeletal abnormalities. Proc NatlAcad Sci US A. 1998;95(9):5372-5377.

56. Segawa H, et al. Npt2a and Npt2c in mice play distinct and synergistic roles in inorganic phosphate metabolism and skeletal development. Am J Physiol Renal Physiol. 2009;297(3):F671-F678.

57. Shimada T, et al. Targeted ablation of Fgf23 demonstrates an essential physiological role of FGF23 in phosphate and vitamin D metabolism. JClin Invest. 2004;113(4):561-568.

58. Christov M, et al. Plasma FGF23 levels increase rapidly after acute kidney injury. Kidney Int . 2013;84(4):776-785.

59. Cosgrove D, et al. Collagen COL4A3 knockout: a mouse model for autosomal Alport syndrome. Genes Dev. 1996;10(23):2981-2992.

60. Christov M, et al. Inducible podocyte-specific deletion of CTCF drives progressive kidney disease and bone abnormalities. JCI Insight . 2018;3(4):e95091.

61. Brown CD, et al. Characterisation of human tubular cell monolayers as a model of proximal tubular xenobiotic handling. Toxicol Appl Pharmacol. 2008;233(3):428-438.

62. Guo J, et al. Activation of a non-cAMP/PKA signaling pathway downstream of the PTH/PTHrP receptor is essential for a sustained hypophosphatemic response to PTH infusion in male mice. Endocrinology. 2013;154(5):1680-1689. 